\title{
Hair mercury levels in relation to fish consumption among Vietnamese in Hanoi
}

\author{
Van Anh Thi Hoang ${ }^{1,2}$, Hien Thu Thi Do3, Tetsuro Agusa2, Chihaya Koriyama ${ }^{4}$, \\ Suminori Akiba ${ }^{4}$, Yasuhiro Ishibashi ${ }^{2}$, Mineshi Sakamoto ${ }^{5}$ and Megumi Yamamoto ${ }^{1,2}$ \\ 'Department of Basic Medical Science, National Institute for Minamata Disease, \\ 4058-18 Hama, Minamata, Kumamoto 867-0008, Japan \\ ${ }^{2}$ Graduate School of Environmental and Symbiotic Science, Prefectural University of Kumamoto, \\ 3-1-100 Tsukide, Higashi-ku, Kumamoto 862-8502, Japan \\ ${ }^{3}$ General Planning Department, National Hospital of Dermatology and Venereology, \\ 15 A Phuong Mai, Hanoi, Vietnam \\ ${ }^{4}$ Department of Epidemiology and Preventive Medicine, Kagoshima University Graduate School of Medical and \\ Dental Sciences, 8-35-1 Sakuragaoka, Kagoshima 890-8544, Japan \\ ${ }^{5}$ Department of Environmental Science and Epidemiology, National Institute for Minamata Disease, \\ 4058-18 Hama, Minamata, Kumamoto 867-0008, Japan
}

(Received June 23, 2017; Accepted July 30, 2017)

\begin{abstract}
People are exposed to methylmercury (MeHg) mainly through fish consumption, which is increasing in Vietnam. However, little information is available on estimating the health risk of $\mathrm{MeHg}$ exposure through fish consumption in Vietnam. The present study examined the association between mercury $(\mathrm{Hg})$ levels in hair and selenium (Se) levels in toenails of 196 Vietnamese people and their fish consumption, using a dietary questionnaire to obtain information pertinent for assessing health risk owing to MeHg exposure. The geometric mean of $\mathrm{Hg}$ levels in the hair of males and females was $617 \mathrm{ng} / \mathrm{g}$ and $575 \mathrm{ng} / \mathrm{g}$, respectively. We found that $\mathrm{Hg}$ levels in the hair of $98 \%$ of the Vietnamese study subjects were lower than the provisional tolerable weekly intake for $\mathrm{MeHg}(1.6 \mu \mathrm{g} \mathrm{Hg} / \mathrm{kg}$ body weight; which is equivalent to a hair $\mathrm{Hg}$ concentration of approximately $2,300 \mathrm{ng} / \mathrm{g}$, with an uncertainty factor of 6.4 ). There were significant differences in the age-adjusted geometric mean of $\mathrm{Hg}$ levels found in hair from females related to their frequency of freshwater fish consumption. The levels of $\mathrm{Hg}$ in hair and Se in toenails increased with an increased frequency of marine fish consumption, and both showed a significant positive correlation in subjects who consumed marine fish $\geq$ once/week. This is the first cross-sectional study to investigate the association between hair $\mathrm{Hg}$ levels and fish consumption in Vietnam. These findings provide valuable information for future assessments of the health risk of $\mathrm{MeHg}$ exposure through fish consumption in Vietnam.
\end{abstract}

Key words: Methylmercury, Fish consumption, Vietnamese, Selenium

\section{INTRODUCTION}

Methylmercury (MeHg) is a well-known neurotoxin (World Health Organization, 2008, 2010). The target organ for $\mathrm{MeHg}$ toxicity is the brain, and the developing brain is especially sensitive to $\mathrm{MeHg}$ exposure. Hence, fetuses, newborn and young children are especially susceptible to $\mathrm{MeHg}$ exposure. Parents, pregnant women, and women of childbearing age should be aware of the potential risk of $\mathrm{MeHg}$. People are primarily exposed to
$\mathrm{MeHg}$ through consumption of fish and marine mammals (World Health Organization, 2008, 2010). Consequently, assessment of $\mathrm{MeHg}$ exposure is an important public health issue and evaluation of associated health risks is needed, especially for people who consume large amounts of fish and other seafood containing high concentrations of mercury $(\mathrm{Hg})$.

Selenium $(\mathrm{Se})$ is an essential trace nutrient in humans that participates in antioxidant defense mechanisms, thyroid hormone metabolism, and the redox control of intra-

Correspondence: Megumi Yamamoto (E-mail: yamamoto@nimd.go.jp) 
cellular reactions (Agency for Toxic Substances and Disease Registry, 2003). People consume Se mainly through seafood, with its organic form comprising the greatest proportion of total dietary intake (Agency for Toxic Substances and Disease Registry, 2003; Roman et al., 2014). Selenium plays an important role providing an antagonistic effect on $\mathrm{Hg}$ toxicity in various tissues and organs of rodents, fish and marine mammals (Peterson et al., 2009; Khan and Wang, 2009; Sakamoto et al., 2015). The correlation between Se concentrations in human specimens and health risk has been widely studied in the environmental health science of MeHg (Mozaffarian and Rimm, 2006).

Recently, fish consumption is increasing in Vietnam (Food and Agriculture Organization of the United Nations, 2004). The rise in demand for fish and fishery products in Vietnam is caused by two main factors, population and income growth (Food and Agriculture Organization of the United Nations, 2004). Vietnam is ranked sixth place in eight Southeast Asian countries for the consumption of fish and fish products as determined by household surveys (Needham and Funge-Smith, 2015). Most commercial fish and other seafood in Vietnam are locally harvested (Food and Agriculture Organization of the United Nations, 2005). Food and Agriculture Organization of the United Nations (2004) reported that a strong and sustained demand for fish and fishery products was expected from the Vietnamese population. However, little information is available on estimating the health risk of $\mathrm{MeHg}$ exposure through fish consumption in Vietnam.

Hair is the preferred biological sample for the assessment of $\mathrm{MeHg}$ exposure in many studies because it provides a simple, integrative, and non-invasive sample for estimating long-term average exposure. Hair contains a higher concentration of $\mathrm{Hg}$ than blood or urine, allowing easier detection of $\mathrm{Hg}$ (Srogi, 2007). Total mercury (T-Hg) in hair is about 250 to 300 times higher than the blood concentration of $\mathrm{Hg}$ at the corresponding moment of hair formation (World Health Organization, 2008, 2010). The $\mathrm{MeHg}$ usually constitutes at least $80 \%$ of $\mathrm{T}-\mathrm{Hg}$ analyzed in hair from fish consumers (McDowell et al., 2004). Nail clippings also have advantages compared with other biological materials and are thought to reflect longterm exposures (Slotnick and Nriagu, 2006; Koriyama et al., 2008).

In the present study, we examined the association between $\mathrm{Hg}$ levels in hair or Se levels in toenails and fish consumption using a dietary questionnaire for subjects recruited in Hanoi, to obtain information pertinent for assessing the potential health risk from $\mathrm{MeHg}$ exposure in Vietnamese. In addition, $\mathrm{T}-\mathrm{Hg}$ and $\mathrm{MeHg}$ concen- trations in several commercially canned seafood products in Hanoi were determined for a preliminary survey.

\section{MATERIALS AND METHODS}

\section{Sample collection and preparation}

A total of 196 Vietnamese people with no occupational exposure to $\mathrm{Hg}$ compounds were selected from staff $(n=98)$, and outpatients with acne $(n=29)$, tinea $(n=29)$ or sexually transmitted infections $(n=40)$, at the National Hospital of Dermatology and Venereology in Hanoi from 2015 to 2016. To recruit subjects from wide areas and with various characteristics, we selected a national referral hospital (National Hospital of Dermatology and Venereology), which had outpatients from Hanoi and other provinces in northern Vietnam. All subjects agreed to participate and gave their consent after an explanation of study objectives and methods. Subjects were 16 to 55 years old (mean $27.8 \pm 7.4$ ). For hair collection, approximately 50 full-length strands of hair were cut close to the scalp in the occipital area and stored in clean polyethylene bags. Clipped toenail samples were stored in a separate plastic envelope with the identification number of the corresponding subject. Hair and toenail samples were transferred to the National Institute for Minamata Disease, Japan, and stored at room temperature before analysis. This study was approved by the ethics committees of the National Institute for Minamata Disease, Kagoshima University, Prefectural University of Kumamoto (Japan) and National Hospital of Dermatology and Venereology (Vietnam).

\section{Frequency and amount of fish consumption}

General information (age, gender, bodyweight, height, occupation, education, marital status, hair treatment, and habits of smoking, alcohol drinking and eating out), frequency of fish consumption and amount of fish consumed per time were estimated for each subject using a food frequency questionnaire (FFQ). The FFQ was used to evaluate the frequency of freshwater and marine fish consumption during the past year. There were three alternatives for each species of fish: $\geq 4$ times/week, 1-3 times/week, never or $<1$ time/week. Regarding the amount of fish consumed per time, there were two alternatives for each species of fish: $\geq 50 \mathrm{~g} /$ time and $<50 \mathrm{~g} /$ time. We used food models of fish $(50 \mathrm{~g})$ and pictures of fish commonly consumed in Hanoi to increase the accuracy of the survey.

\section{Reagents}

Analytical grade reagents were used in this study. Five $\mathrm{M}$ sodium hydroxide $(\mathrm{NaOH})$ solution, hydrogen bro- 
Hair mercury levels related to fish consumption in Vietnamese

mide $(\mathrm{HBr})$, copper (II) chloride dihydrate $\left(\mathrm{CuCl}_{2} \cdot 2 \mathrm{H}_{2} \mathrm{O}\right)$, nitric acid $\left(\mathrm{HNO}_{3}\right)$, methyl isobutyl ketone (MIBK: atomic absorption spectrometry grade), hexane (HPLC analysis grade), toluene (HPLC analysis grade) and L-cysteine (Cys) were purchased from Kanto Chemical Co. (Tokyo, Japan). Methylmercury chloride $(\mathrm{MeHgCl} ;>98 \%$ purity) was obtained from Tokyo Chemical Industry (Tokyo, Japan). Sodium acetate trihydrate ( $\mathrm{NaOAc:} \mathrm{Emsure}$ grade) was purchased from Merck (Darmstadt, Germany). The $\mathrm{Hg}$ standard solution $\left(\mathrm{Hg} 1000 \mathrm{mg} / \mathrm{L}, \mathrm{HgCl}_{2}\right.$ in $0.1 \mathrm{~mol} / \mathrm{L} \mathrm{HNO}_{3}$ ) was purchased from Wako Pure Chemical Industries (Osaka, Japan). Ultra-pure water was prepared using a Milli-Q system (Merck Millipore, Tokyo, Japan). Cys (0.1\%) and Cys (0.2\%)-NaOAc (2\%) solutions were freshly prepared for each experiment.

\section{Determination of total mercury concentration in hair}

The T-Hg in the $3 \mathrm{~cm}$ proximal end of scalp hair was determined using direct thermal decomposition $\mathrm{Hg}$ analyzers MA-3000 (Nippon Instruments, Tokyo, Japan). Detection was performed using cold-vapor atomic absorption spectroscopy at a wavelength of $253.7 \mathrm{~nm}$. The detection limit of $\mathrm{Hg}$ was $0.1 \mathrm{ng}$. A standard $\mathrm{Hg}$ working solution for the calibration curve was prepared using the $\mathrm{Hg}$ standard solution $\left(\mathrm{Hg} 1,000 \mathrm{mg} / \mathrm{L}, \mathrm{HgCl}_{2}\right.$ in 0.1 $\mathrm{mol} / \mathrm{L} \mathrm{HNO}_{3}$ ) according to the manufacturer's protocol (Nippon Instruments). The certified reference material (CRM) of hair (NIES CRM No.13) was measured as a quality control, and the determined T-Hg level of $4.41 \mu \mathrm{g} / \mathrm{g} \pm$ $0.03 \mu \mathrm{g} / \mathrm{g}(\mathrm{n}=5)$ was within the certified range of 4.42 $\pm 0.20 \mu \mathrm{g} / \mathrm{g}$. A coefficient of variation $(\mathrm{CV})$ of $0.7 \%$ was obtained from five repeated measurements using standard hair.

\section{Determination of total mercury and methylmercury in canned fish}

Canned fish were obtained from supermarkets in Hanoi, Vietnam. Using company names shown on the label, canned fish samples included: sardines in tomato sauce from companies A, B and C; mackerel in tomato sauce from company $\mathrm{D}$; tuna in oil from companies $\mathrm{E}$ and $\mathrm{F}$; yellowfin tuna chunks in vegetable oil from company $\mathrm{G}$, light tuna chunks in oil from company $\mathrm{H}$; tuna in vegetable oil from company I; tuna chunks in brine from company $\mathrm{J}$ ( $\mathrm{n}=1$ for each). Muscles of canned fish samples were weighed (1 g, wet weight) and transferred to $15 \mathrm{~mL}$ polypropylene (PP) tubes then kept at $-30^{\circ} \mathrm{C}$ until analysis.

Extraction of $\mathrm{T}-\mathrm{Hg}$ and $\mathrm{MeHg}$ from canned fish samples followed the protocol described previously (Miyamoto et al., 2010; Yoshimoto et al., 2016). Briefly, the muscle of canned fish samples was solubilized with $0.1 \%$ Cys solution $(1 \mathrm{~mL})$ and $5 \mathrm{M} \mathrm{NaOH}(1 \mathrm{~mL})$, then incubated at $80^{\circ} \mathrm{C}$ for $1 \mathrm{hr}$ with vortexing every $10 \mathrm{~min}$. After cooling to room temperature, each solubilized sample solution was made up to $5 \mathrm{~mL}$ with distilled water. MIBK $(6 \mathrm{~mL})$ was then added and the sample solution was shaken at $220 \mathrm{rpm}$ for $10 \mathrm{~min}$. After centrifugation $(1,750 \times \mathrm{g}$, $10 \mathrm{~min})$, the upper MIBK layer was removed and the remaining solubilized solution was washed with hexane ( $5 \mathrm{~mL})$, followed by shaking (220 rpm, $5 \mathrm{~min}$ ) and centrifugation $(1,750 \times \mathrm{g}, 5 \mathrm{~min})$ to obtain the solubilized and degreased sample solution, which was used for the determination of T-Hg. In the next step, $2 \mathrm{~mL}$ of the solubilized and degreased sample solution was added to $2 \mathrm{~mL}$ of $5 \mathrm{M} \mathrm{HBr}, 0.5 \mathrm{~mL}$ of $2 \mathrm{M} \mathrm{CuCl}_{2}$ and $6 \mathrm{~mL}$ of toluene, followed by shaking (10 $\mathrm{min})$. After centrifuging of the sample solution $(1,750 \times \mathrm{g}, 10 \mathrm{~min})$, the upper toluene layer $(5 \mathrm{~mL})$ was transferred to a new $15 \mathrm{~mL}$ PP tube, and $1 \mathrm{~mL}$ of Cys $(0.2 \%)$-NaOAc $(2 \%)$ solution was added, followed by shaking $(5 \mathrm{~min})$, and centrifugation $(1,750 \times \mathrm{g}$, $5 \mathrm{~min})$. After removal of the toluene layer, the reverseextracted Cys (0.2\%)-NaOAc (2\%) solution was used to measure $\mathrm{MeHg}$.

The $\mathrm{T}-\mathrm{Hg}$ and $\mathrm{MeHg}$ concentrations in extracts of canned fish samples were determined using direct thermal decomposition $\mathrm{Hg}$ analyzers MA-3000 (Nippon Instruments). Total $\mathrm{Hg}$ and $\mathrm{MeHg}$ were measured in cod fish CRM (National Institute of Advanced Industrial Science and Technology, 2010) for quality control. The mean values $(\mathrm{n}=5)$ measured for $\mathrm{T}-\mathrm{Hg}$ and $\mathrm{MeHg}$ in cod fish were $0.62 \mu \mathrm{g} / \mathrm{g} \pm 0.01$ and $0.59 \mu \mathrm{g} / \mathrm{g} \pm$ $0.01 \mu \mathrm{g} / \mathrm{g}$, respectively, which were within the certified range of $0.61 \pm 0.02 \mu \mathrm{g} / \mathrm{g}$ and $0.58 \pm 0.02 \mu \mathrm{g} / \mathrm{g}$, respectively. A CV of $0.8 \%$ and $0.9 \%$ was obtained for $\mathrm{T}-\mathrm{Hg}$ and $\mathrm{MeHg}$, respectively, after five replicate measurements using cod fish CRM.

\section{Determination of selenium concentration in toenail}

A toenail sample was washed by sonication in $0.3 \%$ polyoxyethylene lauryl ether and subsequently dried for $12 \mathrm{hr}$ at $80^{\circ} \mathrm{C}$. The sample was digested in $10 \mathrm{~mL}$ of $35 \%$ $\mathrm{HNO}_{3}$ in a Teflon polytetrafluoroethylene tube in a closed vessel microwave system (Ethos Easy, Milestone Srl, Sorisole, BG, Italy). The concentration of Se was determined with an inductively coupled plasma mass spectrometer (Agilent 7500cs, Agilent Technologies, Tokyo, Japan). Accuracy of the method was assessed using CRM for hair (NIES CRM No.13). Recovery of Se ranged from $92-98 \%(n=3)$. 


\section{Statistical analysis}

Sheehan et al. (2014) suggested that population $\mathrm{Hg}$ biomarker distributions are often skewed, so the central tendency is best captured by geometric means or medians. As the distribution of $\mathrm{Hg}$ concentrations in hair was skewed and had a long upper tail, we calculated the geometric means for hair $\mathrm{Hg}$ concentrations and their corresponding 95\% confidence intervals (CIs). We used log-transformed $\mathrm{Hg}$ values for statistical analyses. A multivariable regression model was used to examine the association of $\mathrm{Hg}$ levels with fish consumption and other personal characteristics after adjusting for the effect of age. The associations between log-transformed $\mathrm{Hg}$ in hair and age, and log-transformed $\mathrm{Hg}$ in hair and Se levels in toenails were assessed using the Spearman rank correlation coefficient. Stata version 14 software (StataCorp LP, College Station, TX, USA) was used for all statistical analyses. Figures were drawn using GraphPad Prism 7 software (Version 7.00, GraphPad Software Inc., La Jolla, CA, USA). $P$ values for heterogeneity were obtained using the likelihood ratio test, and $p$ values for trend were obtained using the multivariable regression model. All $p$ values presented are two-sided and a $p$ value of less than 0.05 was considered statistically significant.

\section{RESULTS}

\section{Relationship between mercury concentrations in hair and personal characteristics}

Figure 1 shows the distribution of $\mathrm{Hg}$ concentrations in hair for males and females. The distributions of $\mathrm{Hg}$ concentrations in hair from both males and females were skewed and had long upper tails. The geometric means of $\mathrm{Hg}$ levels in males and female were $617 \mathrm{ng} / \mathrm{g}$ and $575 \mathrm{ng} / \mathrm{g}$, respectively. The present study found no significant difference in $\mathrm{Hg}$ concentrations in hair from males and females. In addition, there was no significant difference in hair $\mathrm{Hg}$ concentrations among staff and outpatients with acne, tinea or sexually transmitted infections (data not shown). The highest geometric mean of $\mathrm{Hg} \mathrm{lev-}$ els in hair was found in staff $(603 \mathrm{ng} / \mathrm{g})$, and the lowest $\mathrm{Hg}$ level was found in outpatients with acne (562 ng/g).

Figure 2 shows the relationships between age and log-transformed $\mathrm{Hg}$ concentrations in hair for males and females. There were significant positive correlations between log-transformed $\mathrm{Hg}$ concentrations in hair and age for males $(r=0.37, p<0.01)$ and females $(r=0.33$, $\mathrm{p}<0.01$ ). The log-transformed $\mathrm{Hg}$ concentrations in hair tended to increase with age.

The age-adjusted geometric means of $\mathrm{Hg}$ levels in hair from males and females grouped by personal character-
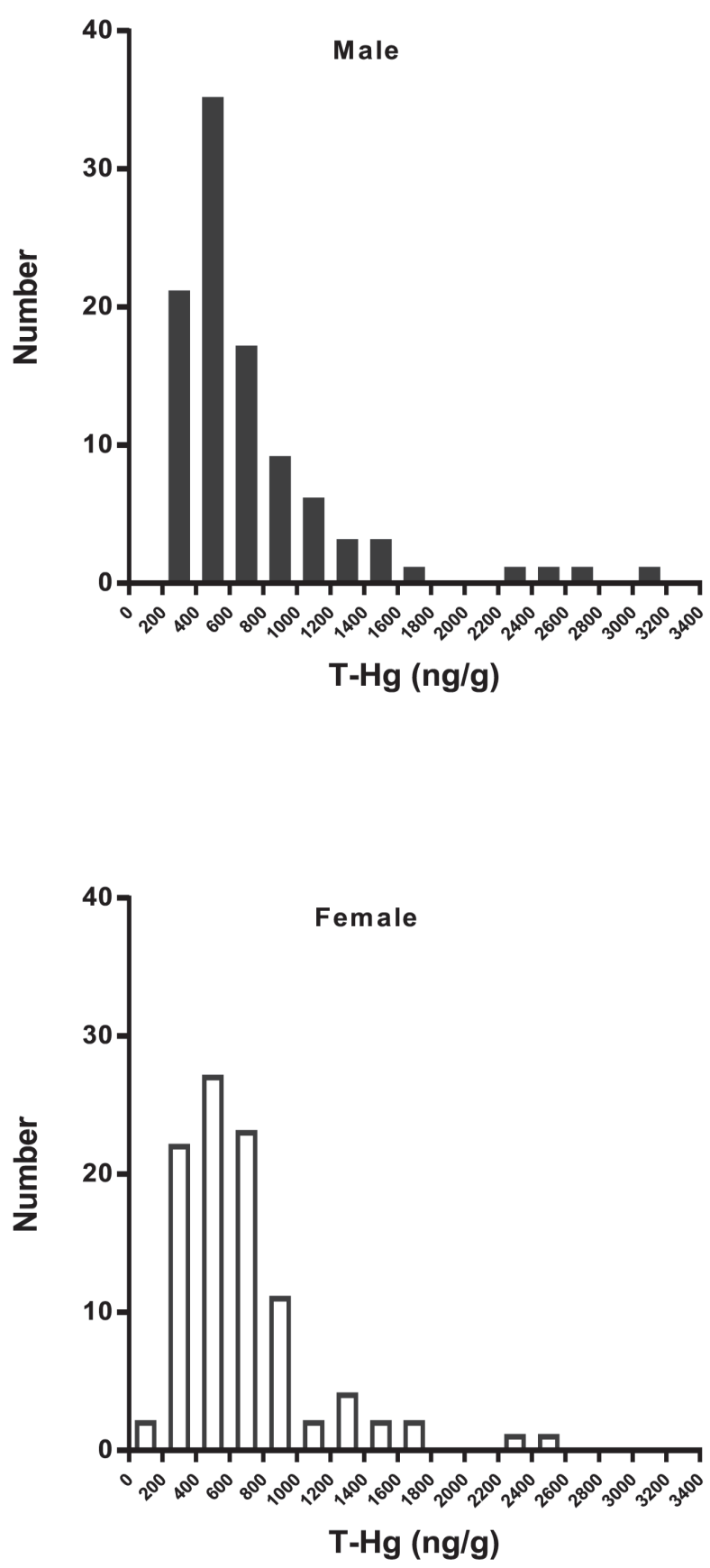

Fig. 1. Distribution histograms of mercury concentrations in hair of males and females.

Males: $\mathrm{n}=99$

Females: $\mathrm{n}=97$

istics are shown in Table 1. In the male population, there were no significant associations between the age-adjusted geometric mean of $\mathrm{Hg}$ levels and other characteristics. In contrast, female samples exhibited significant differences 
Hair mercury levels related to fish consumption in Vietnamese
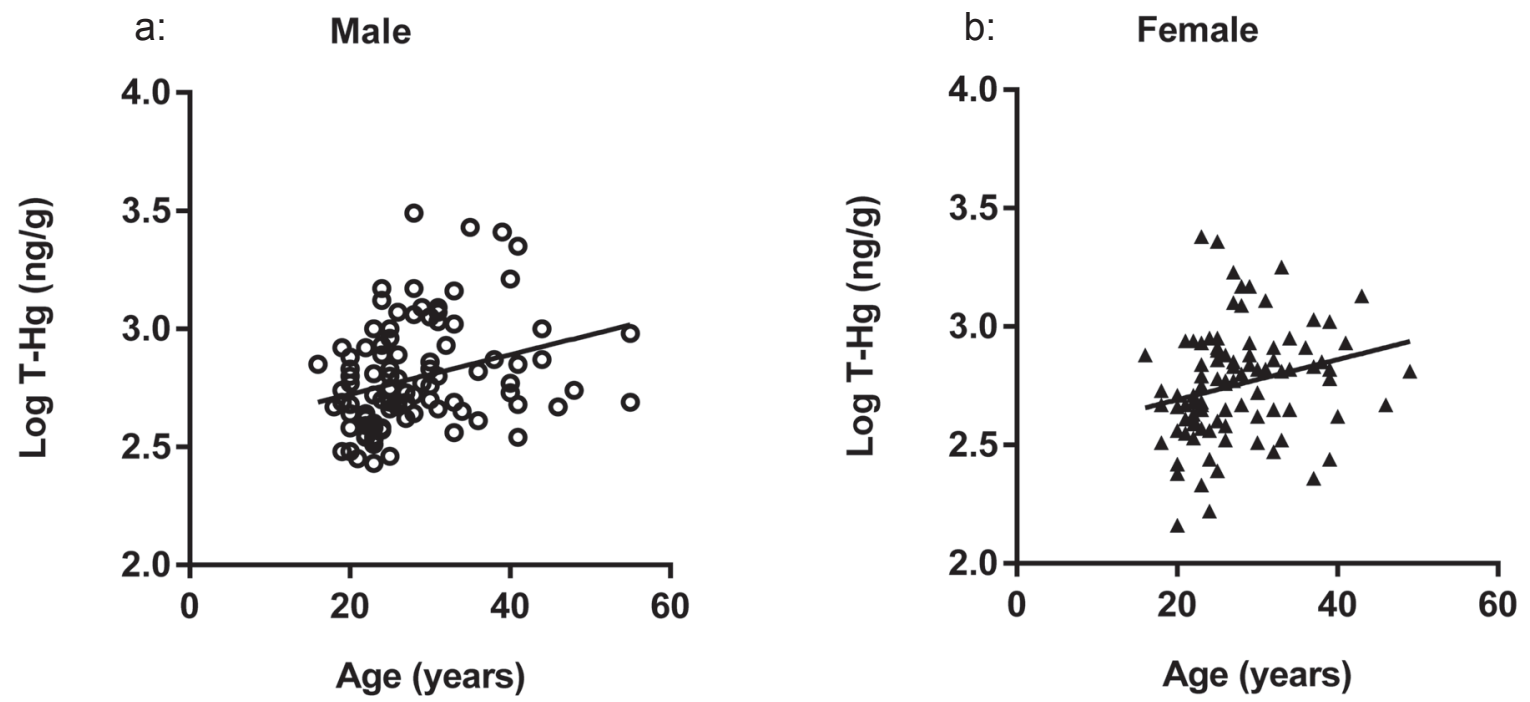

Fig. 2. Relationship between age and log-transformed mercury concentrations in hair of males and females.

a. Relationship between age and log-transformed mercury concentrations in hair of males. $\circ$ : Male: $\mathrm{n}=99, \mathrm{r}=0.37, p<0.01$;

b. Relationship between age and log-transformed mercury concentrations in hair of females.

$\Delta$ : Female: $\mathrm{n}=97, \mathrm{r}=0.33, p<0.01$.

in the age-adjusted geometric means of $\mathrm{Hg}$ levels grouped by occupation and the frequency of eating out. Females grouped as "factory workers and construction workers" and "farmers and craftspeople" had higher Hg levels in hair than those grouped as "state officers and retired state officers" or "lecturers and students". A multivariate regression model adjusting for the effect of age showed that females who ate out $<3$ times/week had higher $\mathrm{Hg}$ levels in hair than those who ate out $\geq 3$ times/week.

\section{Relationship between mercury concentrations in hair and fish consumption}

Table 2 shows the age-adjusted geometric mean of $\mathrm{Hg}$ levels in hair from males and females grouped by frequency and amount of fish consumption. The female population showed a significant difference in the age-adjusted geometric mean of $\mathrm{Hg}$ levels among all subgroups: frequency of freshwater fish consumption $(p=0.027)$; frequency of marine fish consumption $(p=0.017)$; amount of freshwater fish consumption $(p=0.022)$ and amount of marine fish consumption $(\mathrm{p}=0.033)$. The male population showed significant differences in the age-adjusted geometric mean of hair $\mathrm{Hg}$ levels related to their frequency of freshwater fish consumption $(p=0.019)$.

To investigate the effect of freshwater fish consumption on hair $\mathrm{Hg}$ levels, the age-adjusted geometric mean of $\mathrm{Hg}$ levels in hair from males and females was grouped by a frequency of marine fish consumption of "never or $<1$ time/week", as shown in Table 3. After limiting the subjects who had a frequency of marine fish consumption grouped as "never or $<1$ time/week", there were no significant differences in the age-adjusted geometric means of hair Hg levels between males grouped according to the frequency or amount of freshwater fish consumption. However, there were significant differences in the age-adjusted geometric mean of $\mathrm{Hg}$ levels in hair from females grouped by the frequency of freshwater fish consumption $(p=0.016)$. Females who had a higher fish consumption frequency showed higher age-adjusted geometric mean $\mathrm{Hg}$ levels in hair.

\section{Relationship between mercury concentrations in hair and selenium concentrations in toenails}

Figure 3 shows the relationships between log-transformed $\mathrm{Hg}$ concentrations in hair and Se concentrations in toenails in groups defined by the frequency of freshwater fish and marine fish consumption. There was no significant correlation between log-transformed $\mathrm{Hg}$ concentrations in hair and Se concentrations in toenails in subjects that consumed freshwater fish. However, log-transformed $\mathrm{Hg}$ concentrations in hair and Se concentrations in toenails tended to increase with the increased frequency of 
Table 1. Age-adjusted geometric mean of mercury levels $(\mathrm{ng} / \mathrm{g})$ in hair from males and females in relation to personal characteristics.

\begin{tabular}{|c|c|c|c|c|c|c|c|c|}
\hline \multirow[b]{2}{*}{ Item } & \multicolumn{4}{|c|}{ Male } & \multicolumn{4}{|c|}{ Female } \\
\hline & $\mathrm{N}$ & $\begin{array}{l}\mathrm{GM}^{* *} \\
(\mathrm{ng} / \mathrm{g})\end{array}$ & $95 \% \mathrm{CI}$ & $\mathrm{p}$ & $\mathrm{N}$ & $\begin{array}{l}\mathrm{GM}^{* *} \\
(\mathrm{ng} / \mathrm{g})\end{array}$ & $95 \% \mathrm{CI}$ & $\mathrm{p}$ \\
\hline Total & 99 & 617 & $550-676$ & & 97 & 575 & $513-631$ & \\
\hline \multicolumn{9}{|l|}{ Occupation } \\
\hline State officer and state officer retired & 23 & 603 & $501-692$ & \multirow{5}{*}{0.534} & 38 & 562 & $479-646$ & \multirow{5}{*}{$0.009 *$} \\
\hline Lecturer and student & 23 & 603 & $537-692$ & & 24 & 562 & $501-631$ & \\
\hline Factory workers and construction workers & 18 & 617 & $562-692$ & & 20 & 575 & $501-646$ & \\
\hline Farmer and craftspeople & 12 & 631 & $562-724$ & & 5 & 589 & $490-692$ & \\
\hline Others & 23 & 646 & $537-776$ & & 10 & 589 & $457-759$ & \\
\hline \multicolumn{9}{|l|}{ Age } \\
\hline $16-24$ & 40 & 490 & $372-646$ & \multirow{4}{*}{0.051} & 39 & 479 & $355-661$ & \multirow{4}{*}{$0.011 *$} \\
\hline $25-29$ & 25 & 617 & $257-676$ & & 28 & 575 & $513-631$ & \\
\hline $30-39$ & 21 & 759 & $589-955$ & & 25 & 676 & $479-955$ & \\
\hline $40-55$ & 13 & 933 & $575-1479$ & & 5 & 794 & $427-1514$ & \\
\hline \multicolumn{9}{|l|}{ Education } \\
\hline Less than high school & 13 & 617 & $490-794$ & \multirow{3}{*}{0.356} & 6 & 525 & $372-741$ & \multirow{3}{*}{0.896} \\
\hline High school & 19 & 617 & $550-708$ & & 15 & 550 & $468-646$ & \\
\hline Degree/diploma & 67 & 617 & $550-692$ & & 76 & 575 & $513-646$ & \\
\hline \multicolumn{9}{|l|}{ Marital status } \\
\hline Single & 50 & 589 & $501-692$ & \multirow{2}{*}{0.433} & 46 & 537 & $447-646$ & \multirow{2}{*}{0.46} \\
\hline Married & 49 & 646 & $550-759$ & & 51 & 589 & $501-708$ & \\
\hline \multicolumn{9}{|l|}{ Smoke } \\
\hline Smoker & 32 & 589 & $501-708$ & \multirow{2}{*}{0.57} & 1 & 562 & N/A & \multirow{2}{*}{ N/A } \\
\hline Non-Smoker & 67 & 631 & $562-708$ & & 96 & 562 & $513-631$ & \\
\hline \multicolumn{9}{|l|}{ Hair treatment } \\
\hline Treatment & 4 & 513 & $302-851$ & \multirow{2}{*}{0.431} & 62 & 550 & $479-631$ & \multirow{2}{*}{0.468} \\
\hline Non-treatment & 95 & 631 & $562-692$ & & 35 & 603 & $501-708$ & \\
\hline \multicolumn{9}{|l|}{ Alcohol } \\
\hline Drinker & 84 & 617 & $550-692$ & \multirow{2}{*}{0.844} & 11 & 457 & $339-631$ & \multirow{2}{*}{0.158} \\
\hline Non-drinker & 15 & 631 & $490-813$ & & 86 & 589 & $525-646$ & \\
\hline \multicolumn{9}{|l|}{ Eat out } \\
\hline Less than 3 times/week & 65 & 603 & $525-676$ & \multirow{2}{*}{0.322} & 74 & 617 & $550-692$ & \multirow{2}{*}{$0.001^{*}$} \\
\hline 3 or more than 3 times/week & 34 & 661 & $562-794$ & & 23 & 437 & $355-537$ & \\
\hline
\end{tabular}

*Significant difference. Males: $\mathrm{n}=99$; Females: $\mathrm{n}=97$. ** Geometric mean

marine fish consumption, and showed a positive correlation in subjects that consumed marine fish $\geq$ once/week $(\mathrm{r}=0.37, \mathrm{p}=0.047)$.

\section{Species of consumed fish and mercury concentrations in canned fish}

Table 4 summarizes the species of fish commonly consumed by males and females examined in Hanoi. During one year, 93 males and 96 females consumed freshwater fish. The freshwater fishes consumed by males and females were common carp, roho labeo and tilapia. During one year, 56 males and 63 females consumed marine fish. Males typically consumed mackerel, salmon and scad, whereas females usually consumed basa, mackerel and scad. Tuna was the second lowest and least consumed fish species in the male and female populations, respectively.

Table 5 summarizes the $\mathrm{Hg}$ concentrations determined in the muscle of canned fish purchased in Hanoi. The highest $\mathrm{Hg}$ concentration was found in yellowfin tuna chunks in vegetable oil (T-Hg: $622.9 \mathrm{ng} / \mathrm{g}$; $\mathrm{MeHg}$ : $589.5 \mathrm{ng} / \mathrm{g}$ ) and the lowest $\mathrm{Hg}$ concentration was found in the muscle of sardines in tomato sauce from company C (T-Hg: $5.1 \mathrm{ng} / \mathrm{g}$; MeHg: $5.1 \mathrm{ng} / \mathrm{g}$ ). The values of $\mathrm{MeHg}$ as a percentage of $\mathrm{T}-\mathrm{Hg}$ in all canned fish ranged from $90.4 \%$ to $100 \%$. 
Hair mercury levels related to fish consumption in Vietnamese

Table 2. Age-adjusted geometric mean of mercury levels (ng/g) in hair from males and females grouped by frequency and amount of fish consumption.

\begin{tabular}{|c|c|c|c|c|c|c|c|c|c|c|c|}
\hline \multirow{3}{*}{ Item } & & \multicolumn{5}{|c|}{ Male } & \multicolumn{5}{|c|}{ Female } \\
\hline & & \multicolumn{5}{|c|}{$\mathrm{P}$ values for } & \multicolumn{5}{|c|}{$\mathrm{P}$ values for } \\
\hline & & $\mathrm{N}$ & $\begin{array}{l}\mathrm{GM}^{* *} \\
(\mathrm{ng} / \mathrm{g})\end{array}$ & $95 \% \mathrm{CI}$ & Heterogeneity & Trend & $\mathrm{N}$ & $\begin{array}{l}\mathrm{GM}^{* *} \\
\text { (ng/g) }\end{array}$ & $95 \% \mathrm{CI}$ & Heterogeneity & Trend \\
\hline \multirow{8}{*}{$\begin{array}{l}\text { Frequency of } \\
\text { consumption }\end{array}$} & Freshwater fish & & & & \multirow{4}{*}{$0.019^{*}$} & \multirow{4}{*}{$0.028^{*}$} & & & & \multirow{4}{*}{$0.027 *$} & \multirow{4}{*}{$0.009 *$} \\
\hline & Never or $<1$ time/week & 16 & 513 & $417-617$ & & & 7 & 417 & $324-537$ & & \\
\hline & 1-3 times/week & 62 & 617 & $550-676$ & & & 70 & 550 & $490-603$ & & \\
\hline & $\geq 4$ times/week & 21 & 741 & $617-891$ & & & 20 & 724 & $589-871$ & & \\
\hline & Marine fish & & & & \multirow{4}{*}{0.163} & \multirow{4}{*}{0.117} & & & & \multirow{4}{*}{$0.017 *$} & \multirow{4}{*}{0.062} \\
\hline & Never or $<1$ time/week & 69 & 589 & $525-661$ & & & 58 & 525 & $457-603$ & & \\
\hline & 1-3 times/week & 24 & 676 & $589-776$ & & & 36 & 631 & $537-724$ & & \\
\hline & $\geq 4$ times/week & 6 & 776 & $575-1023$ & & & 3 & 759 & $550-1023$ & & \\
\hline \multirow{6}{*}{$\begin{array}{l}\text { Amount of } \\
\text { consumption }\end{array}$} & Freshwater fish & & & & \multirow{3}{*}{0.963} & & & & & \multirow{3}{*}{$0.022 *$} & \\
\hline & Never or $<50 \mathrm{~g} /$ time & 25 & 617 & $513-759$ & & & 14 & 427 & $324-562$ & & \\
\hline & $\geq 50 \mathrm{~g} /$ time & 74 & 617 & $550-692$ & & & 83 & 603 & $537-661$ & & \\
\hline & Marine fish & & & & \multirow{3}{*}{0.642} & & & & & \multirow{3}{*}{$0.033^{*}$} & \\
\hline & Never or $<50 \mathrm{~g} /$ time & 59 & 603 & $537-692$ & & & 50 & 513 & $437-589$ & & \\
\hline & $\geq 50 \mathrm{~g} /$ time & 40 & 631 & $550-741$ & & & 47 & 631 & $550-741$ & & \\
\hline
\end{tabular}

*Significant difference. Males: $\mathrm{n}=99$; Females: $\mathrm{n}=97$. ** Geometric mean

Table 3. Age-adjusted geometric mean of mercury levels $(\mathrm{ng} / \mathrm{g})$ in hair from subjects with a frequency of marine fish consumption never or $<$ once/week.

\begin{tabular}{|c|c|c|c|c|c|c|c|c|c|c|c|}
\hline \multirow{3}{*}{ Item } & & \multicolumn{5}{|c|}{ Male } & \multicolumn{5}{|c|}{ Female } \\
\hline & & \multicolumn{5}{|c|}{$\mathrm{P}$ values for } & \multicolumn{5}{|c|}{$\mathrm{P}$ values for } \\
\hline & & $\mathrm{N}$ & $\begin{array}{l}\mathrm{GM}^{* *} \\
(\mathrm{ng} / \mathrm{g})\end{array}$ & $95 \% \mathrm{CI}$ & Heterogeneity & Trend & $\mathrm{N}$ & $\begin{array}{l}\mathrm{GM}^{* *} \\
\text { (ng/g) }\end{array}$ & $95 \% \mathrm{CI}$ & Heterogeneity & Trend \\
\hline \multirow{4}{*}{$\begin{array}{l}\text { Frequency of } \\
\text { consumption }\end{array}$} & Freshwater fish & & & & & & & & & & \\
\hline & Never or $<1$ time/week & 13 & 513 & $407-646$ & \multirow{3}{*}{0.218} & \multirow{3}{*}{0.18} & 7 & 380 & $282-501$ & \multirow{3}{*}{$0.016^{*}$} & \multirow{3}{*}{$0.015^{*}$} \\
\hline & 1-3 times/week & 45 & 589 & $525-661$ & & & 39 & 501 & $447-575$ & & \\
\hline & $\geq 4$ times/week & 11 & 676 & $537-851$ & & & 12 & 676 & $525-871$ & & \\
\hline \multirow{3}{*}{$\begin{array}{l}\text { Amount of } \\
\text { consumption }\end{array}$} & Freshwater fish & & & & \multirow{3}{*}{0.507} & & & & & \multirow{3}{*}{0.098} & \\
\hline & Never or $<50 \mathrm{~g} /$ time & 18 & 617 & $501-776$ & & & 11 & 417 & $302-562$ & & \\
\hline & $\geq 50 \mathrm{~g} /$ time & 51 & 575 & $501-646$ & & & 47 & 550 & $468-631$ & & \\
\hline
\end{tabular}

*Significant difference; $\mathrm{n}=127 . * *$ Geometric mean

\section{DISCUSSION}

To the best of our knowledge, this is the first crosssectional study to demonstrate the association between hair $\mathrm{Hg}$ levels and fish consumption using a dietary questionnaire to obtain information pertinent for assessing the health risk from $\mathrm{MeHg}$ exposure in Vietnam. In the present study, Hg levels in the hair of $98 \%$ of Vietnamese participants were lower than the provisional tolerable weekly intake (PTWI) for $\mathrm{MeHg}(1.6 \mu \mathrm{g} \mathrm{Hg} / \mathrm{kg}$ body weight, which is equivalent to hair $\mathrm{Hg}$ levels of approximately 2,300 $\mathrm{ng} / \mathrm{g}$, with an uncertainty factor of 6.4) (Joint FAO/WHO Expert Committee on Food Additives, 2003; Sakamoto et al., 2012). There was no significant difference in $\mathrm{Hg}$ concentrations in hair from males and females. Males and females also had no significant difference in the frequency of fish consumption, which may explain the similar levels of $\mathrm{Hg}$ in hair from both sexes.

In the present study, we calculated daily average $\mathrm{MeHg}$ intakes using the age-adjusted geometric mean of $\mathrm{Hg} \mathrm{lev-}$ els in hair from males and females. The calculated daily average $\mathrm{MeHg}$ intakes for males and females (0.062 and $0.058 \mu \mathrm{g} / \mathrm{kg}$ per day, respectively) were lower than the EPA reference dose for $\mathrm{MeHg}$ of $0.1 \mu \mathrm{g} / \mathrm{kg}$ per day (United States Environmental Protection Agency, 1997; National Research Council, 2000). This suggests that males and females in the present study will not have an appreciable risk of deleterious effects from $\mathrm{MeHg}$ expo- 
V.A.T. Hoang et al.

a:

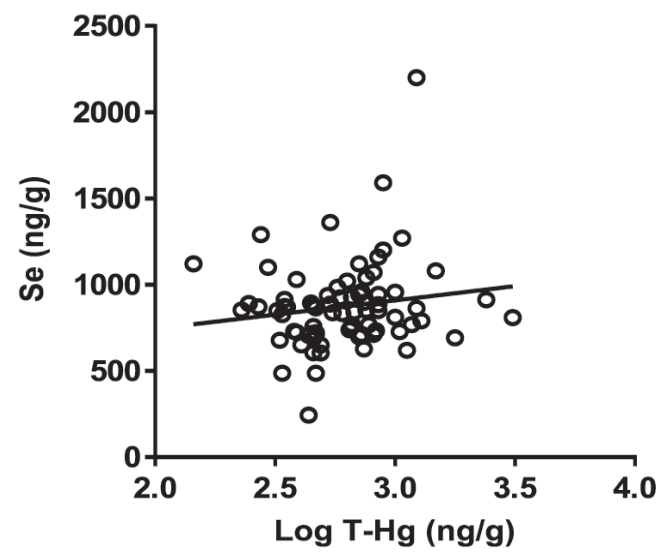

C:

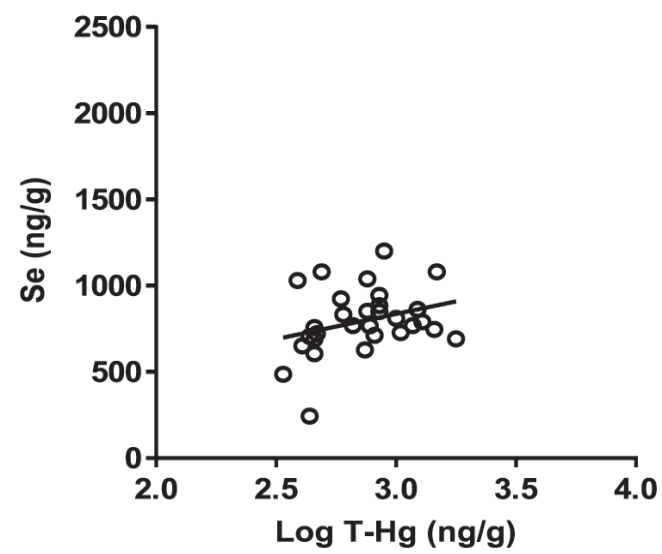

b:

Freshwater fish

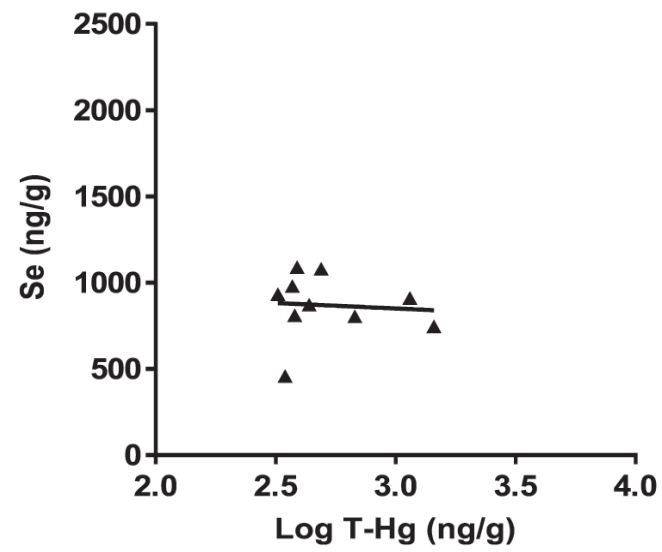

d:

Marine fish

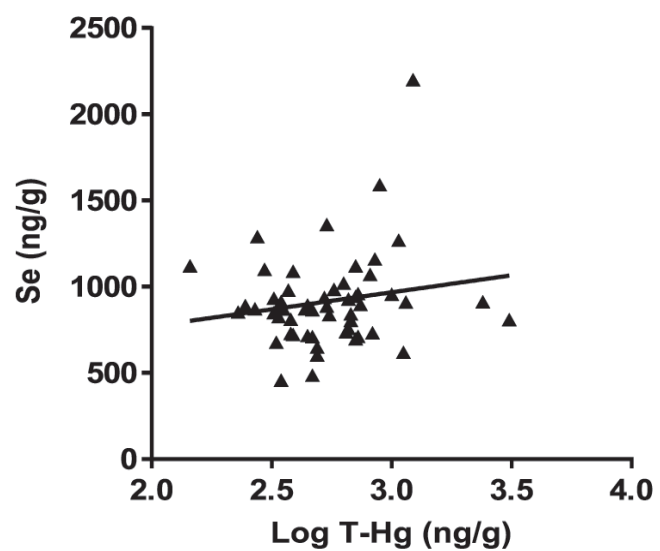

Fig. 3. Relationship between selenium concentrations in toenail and log-transformed mercury concentrations in hair. Frequency of freshwater fish consumption: $\mathrm{n}=86 ; \mathrm{a} . \circ: \geq 1$ time/week: $\mathrm{r}=0.15, p=0.20 ; \mathrm{b}$. $\mathbf{\Delta}:$ Never or $<1$ time/week: $\mathrm{r}=0.15$, $p=0.68$. Frequency of marine fish consumption: $\mathrm{n}=86$; c. $\circ: \geq 1$ time/week: $\mathrm{r}=0.37, p=0.047 ; \mathrm{d}$. $\boldsymbol{\Delta}:$ Never or $<1$ time/ week: $\mathrm{r}=0.13, p=0.36$

Table 4. Fish species mostly commonly consumed by males and females in Hanoi, Vietnam.

\begin{tabular}{lllcccc}
\hline \multirow{2}{*}{ Species } & \multirow{2}{*}{ Scientific name } & \multicolumn{3}{c}{ Male } & \multicolumn{3}{c}{ Female } \\
\cline { 4 - 7 } & & & $\mathrm{N}$ & $\%$ & $\mathrm{~N}$ & \multicolumn{1}{c}{$\%$} \\
\hline \multirow{3}{*}{ Freshwater fish } & Total & & 93 & 100 & 96 & 100 \\
& Tilapia & Oreochromis mosambicus & 72 & 77.4 & 76 & 79.2 \\
& Common carp & Cyprinus carpio Linnaeus & 71 & 76.3 & 70 & 72.9 \\
& Roho labeo & Labeo rohita & 51 & 54.8 & 53 & 55.2 \\
\hline \multirow{3}{*}{ Marine fish } & & 56 & 100 & 63 & 100 \\
& Total & Scomberomorus maculatus & 38 & 67.9 & 39 & 61.9 \\
& Mackerel & Decapterus & 22 & 39.3 & 25 & 39.7 \\
& Scad & Oncorhynchus spp & 17 & 30.4 & 16 & 25.4 \\
& Salmon & Thunnini & 13 & 23.2 & 8 & 12.7 \\
& Tuna & Pangasius bocourti & 9 & 16.1 & 20 & 31.7 \\
\hline
\end{tabular}


Hair mercury levels related to fish consumption in Vietnamese

Table 5. Mercury concentrations (ng/g) in canned fish marketed in Hanoi, Vietnam.

\begin{tabular}{lcccc}
\hline Type & Company & $\begin{array}{c}\mathrm{T}-\mathrm{Hg} \\
\text { (ng/g wet weight) }\end{array}$ & $\begin{array}{c}\mathrm{MeHg} \\
\text { (ng/g wet weight) }\end{array}$ & $\begin{array}{c}\mathrm{MeHg} / \mathrm{T}-\mathrm{Hg} \\
(\%)\end{array}$ \\
\hline Sardines in tomato sauce & $\mathrm{A}$ & 81.6 & 73.8 & 90.4 \\
Sardines in tomato sauce & $\mathrm{B}$ & 7.1 & 6.8 & 95.8 \\
Sardines in tomato sauce & $\mathrm{C}$ & 5.1 & 5.1 & 100 \\
Mackerel in tomato sauce & $\mathrm{D}$ & 8.1 & 8.1 & 100 \\
Tuna in oil & $\mathrm{E}$ & 76.5 & 76.1 & 99.5 \\
Tuna in oil & $\mathrm{F}$ & 54.4 & 52.9 & 97.2 \\
Yellow fin tuna chunks in vegetable oil & $\mathrm{G}$ & 622.9 & 589.5 & 94.6 \\
Light tuna chunks in oil & $\mathrm{H}$ & 63.2 & 62.5 & 98.9 \\
Tuna in vegetable oil & $\mathrm{I}$ & 29.7 & 29.6 & 99.7 \\
Tuna chunks in brine & $\mathrm{J}$ & 78.3 & 76.1 & 97.2 \\
\hline
\end{tabular}

$\mathrm{n}=1$ for each type of canned fish examined

sure through fish consumption.

We found that $\mathrm{Hg}$ levels in hair tended to increase with age for both males and females, consistent with the previously reported correlation between $\mathrm{Hg}$ levels in hair and age (National Research Council, 2000; McDowell et al., 2004). Fish consumption differs with age and older age groups of both males and females eat more fish than younger age groups (Weichselbaum et al., 2013; Otsuka et al., 2014). The present findings were consistent with the reported $\mathrm{Hg}$ exposure through the consumption of freshwater and marine fish in Pakistan (Shah et al., 2016) and $\mathrm{Hg}$ contamination in human hair and fish in Cambodia (Agusa et al., 2005).

In the present study, the age-adjusted geometric means for $\mathrm{Hg}$ levels in hair were significantly different between participants grouped by distinct occupations, and between females grouped by the frequency of eating out. Mercury levels in hair were previously correlated with the frequency of fish consumption (McDowell et al., 2004) and species of fish consumption (Burger, 2000). Hence, differences in the frequency and species of fish consumption may explain the different $\mathrm{Hg}$ levels in hair found in different occupation groups and in females that ate out more frequently.

Yasutake et al. (2003) reported that the treatment of hair samples with a lotion for artificial waving caused a $30 \%$ reduction in $\mathrm{Hg}$ levels. In the present study, we found no significant difference between age-adjusted $\mathrm{Hg}$ levels in hair from subjects who had hair treatment compared with non-treatment in both males and females. This finding agreed with the report that no difference was found in hair $\mathrm{Hg}$ levels among hair treatments and untreated groups in research on hair $\mathrm{Hg}$ levels in U.S children and women of childbearing age (McDowell et al., 2004).

In the present study, there was a significant difference in hair Hg levels between freshwater and marine fish con- sumption. However, inhabitants of Hanoi eat both freshwater and marine fish. Therefore, when subjects were limited to those who consumed marine fish never or $<$ once/week, we found higher Hg levels in the hair of females who had a higher frequency of freshwater fish consumption. Other confounding factors, such as the pattern of fish consumption and dietary interactions (Chapman and Chan, 2000; Bradley et al., 2017), may also explain differences in the hair $\mathrm{Hg}$ levels of females in this study. However, the current questionnaire did not include details of such factors, and further studies are necessary to fully explain the current observations.

We found a significant positive correlation between hair $\mathrm{Hg}$ levels and toenail Se levels in subjects who consumed marine fish $\geq 1$ time/week. Past studies showed that levels of $\mathrm{Hg}$ in hair and $\mathrm{Se}$ in toenails were correlated with blood $\mathrm{Hg}$ and Se levels, respectively (Thomson, 2004; World Health Organization, 2008). Furthermore, levels of both $\mathrm{Hg}$ and $\mathrm{Se}$ in human blood were related to fish consumption (Burger and Gochfeld, 2013). Thomson (2004) reviewed the interaction between Se and heavy metals and found a strong interaction between $\mathrm{Se}$ and $\mathrm{Hg}$ in marine foods. Burger and Gochfeld (2013) concluded that the mean and median of $\mathrm{Se} / \mathrm{Hg}$ molar ratios were higher for marine fish than for all freshwater fish examined. Therefore, a significant positive correlation between hair $\mathrm{Hg}$ levels and toenail Se levels may relate to consumption of marine fish.

In the current study, freshwater fish commonly consumed by males and females included common carp, roho labeo and tilapia, whereas basa, mackerel, salmon and scad were the marine fish typically consumed by both males and females. These fish species are reported to have low levels of $\mathrm{Hg}(<100 \mathrm{ng} / \mathrm{g})$, except for carp with $\mathrm{Hg}$ levels in the intermediate range 100-500 ng/g (Ministry of Health, Labour and Welfare, 2003; World 
Health Organization, 2010; U.S. Food and Drug Administration, 2014). In contrast, tuna have high levels of $\mathrm{Hg}$ (World Health Organization, 2010) and was one of the least consumed fish by Vietnamese males and females. Therefore, low Hg levels in the hair of Vietnamese participants may reflect the consumption of fish with low $\mathrm{Hg}$ levels, and relatively low consumption of high $\mathrm{Hg}$ fish such as tuna.

We determined $\mathrm{T}-\mathrm{Hg}$ and $\mathrm{MeHg}$ concentrations in commercial canned seafood purchased in Hanoi to survey the $\mathrm{Hg}$ concentration in seafood in Vietnam. Canned seafood is a known source of $\mathrm{MeHg}$ exposure (Boadi et al., 2011; Siedlikowski et al., 2016), and canned tuna contains high concentrations of $\mathrm{Hg}$ (Alcala-Orozco et al., 2017). In all samples tested, only $\mathrm{Hg}$ concentrations in the muscle of yellowfin tuna exceeded the maximum level allowed by $\mathrm{WHO}, 500 \mathrm{ng} / \mathrm{g}$ for $\mathrm{MeHg}$ in all types of fish (United Nations Environment Programme, 2002), and permitted by Japanese regulations, $400 \mathrm{ng} / \mathrm{g}$ for T-Hg and $300 \mathrm{ng} / \mathrm{g}$ for MeHg (Notice Kannyu No.99, 1973). The $\mathrm{Hg}$ concentrations in remaining tuna products were lower than the range (100-200 $\mathrm{ng} / \mathrm{g})$ reported by the FDA (Burger and Gochfeld, 2004; U.S. Food and Drug Administration, 2001, 2014). The Hg concentrations in the muscle of mackerels were lower than the levels previously reported (jack mackerel, Orleans: $61 \mathrm{ng} / \mathrm{g}$ and jack jurel mackerel, Chicken of the Sea: $50 \mathrm{ng} / \mathrm{g}$ ) by Shim et al. (2004). Similarly, Hg concentrations in sardines were lower than the $\mathrm{Hg}$ levels in canned sardines $(117 \mathrm{ng} / \mathrm{g}$, $141 \mathrm{ng} / \mathrm{g}$, and $143 \mathrm{ng} / \mathrm{g}$ ) reported by Boadi et al. (2011). The current study found that the percentage of $\mathrm{MeHg}$ in $\mathrm{T}-\mathrm{Hg}$ in canned fish samples ranged from $90.4 \%$ to $100 \%$, which was consistent with levels found in fish, squid and shrimp in previous studies (Bloom, 1992; Yoshimoto et al., 2016; Hoang et al., 2017).

Fish processing in Vietnam plays an important role in producing high value products and contributing to export development. The main Vietnamese fish products include fresh, frozen, dried and canned, as well as fish sauce or paste; frozen fish are the main product, followed by dried fish and fish sauce or paste (Food and Agriculture Organization of the United Nations, 2004). In addition, fish supplies in Vietnam moved from freshwater fishing to freshwater aquaculture or cage culture, which made fish more available for consumption (Food and Agriculture Organization of the United Nations, 2004). Thong and Olsen (2012) reported that fish consumption in Vietnam was related to the quality, price and availability of fish. Therefore, the increased fish consumption in Vietnam may be related to the increased availability, better quality and reduced price of fish.
Recently, we reported that $\mathrm{T}-\mathrm{Hg}, \mathrm{MeHg}$ and Se concentrations in commercial shrimp in Japan, which included Vietnamese black tiger shrimp, were lower than the Japanese regulated level (Notice Kannyu No.99, 1973) of $300 \mathrm{ng} / \mathrm{g}$ for $\mathrm{MeHg}$ in fish (Hoang et al., 2017). Moreover, the average $\mathrm{Se} / \mathrm{Hg}$ molar ratios in the muscle of commercial shrimp were comparatively high (in the range of 16-106). Other studies reported that Se may counteract $\mathrm{Hg}$ toxicity and $\mathrm{Se} / \mathrm{Hg}$ molar ratios above one may increase the protective effect of $\mathrm{Se}$ against $\mathrm{MeHg}$ exposure (Peterson et al., 2009; Khan and Wang, 2009). We showed that shrimp commercially available in Japan do not pose a particularly high risk regarding $\mathrm{MeHg}$ exposure to consumers. Further survey analysis of $\mathrm{MeHg}$ and Se concentrations in commercial fresh seafood in Vietnam is warranted for proper assessment of health risk due to $\mathrm{MeHg}$ exposure.

The strengths of the present study are: (1) this is the first cross-sectional study of the association between hair $\mathrm{Hg}$ levels and Vietnamese fish consumption, using a dietary questionnaire to obtain information for assessing the health risk from $\mathrm{MeHg}$ exposure in Vietnam; (2) we demonstrated that the age-adjusted geometric mean level of $\mathrm{Hg}$ in hair from Vietnamese females was related to freshwater fish consumption; (3) we found significant positive correlations between hair $\mathrm{Hg}$ levels and toenail Se levels among subjects who consumed marine fish $\geq$ once/week. Limitations of this study are: (1) we did not find the main reason for the significant difference in the age-adjusted $\mathrm{Hg}$ levels in hair of Vietnamese females related to the frequency of freshwater fish consumption; (2) we have not analyzed $\mathrm{Hg}$ levels in fresh fish and other seafood from Vietnam, and further studies are required to fully explain the current findings.

In conclusion, the present study has demonstrated that $\mathrm{Hg}$ levels in the hair of $98 \%$ of the Vietnamese participants were lower than the PTWI for $\mathrm{MeHg}$ at $1.6 \mu \mathrm{g}$ $\mathrm{Hg} / \mathrm{kg}$ body weight, with an uncertainty factor of 6.4 (Joint FAO/WHO Expert Committee on Food Additives, 2003). A significant difference in the age-adjusted geometric mean of $\mathrm{Hg}$ levels in hair from females was related to the frequency of freshwater fish consumption. In addition, $\mathrm{Hg}$ levels in hair and Se levels in toenails increased with the increased frequency of marine fish consumption, and showed a significant positive correlation among subjects who consumed marine fish $\geq$ once/week. The values of $\mathrm{MeHg}$ as a percentage of $\mathrm{T}-\mathrm{Hg}$ in canned fish purchased in Vietnam ranged from $90.4 \%$ to $100 \%$. 
Hair mercury levels related to fish consumption in Vietnamese

\section{ACKNOWLEDGMENTS}

The authors are grateful to Drs. Le Huu Doanh, Le Huyen My, Tran Cam Van, Dinh Huu Nghi, Hoang Thi Ngoc Ly, Nguyen Thi Tuyen, Than Trong Tuy, Nguyen Thi Huyen Thuong, and Tran Thi Thanh Tam (National Hospital of Dermatology and Venereology) for their supports in the collection of human samples. We also thank Ms. Hazuki Kashiwagi and Megumi Kudo (National Institute for Minamata Disease) and Ms. Yukiko Uchiyama (Prefectural University of Kumamoto) for their technical assistance. This work was supported by the International Postgraduate Scholarship for Research on Mercury from the Prefectural University of Kumamoto, and a grant from the National Institute for Minamata Disease and Kagoshima University. We thank Charles Allan, PhD, from Edanz Group (www.edanzediting.com/ac) for editing a draft of this manuscript.

Conflict of interest---- The authors declare that there is no conflict of interest.

\section{REFERENCES}

Agency for Toxic Substances and Disease Registry (2003): Toxicological profile for selenium. Atlanta, GA: US Department of Health and Human Services.

Agusa, T., Kunito, T., Iwata, H., Monirith, I., Tana, T.S., Subramanian, A. and Tanabe, S. (2005): Mercury contamination in human hair and fish from Cambodia: levels, specific accumulation and risk assessment. Environ. Pollut., 134, 79-86.

Alcala-Orozco, M., Morillo-Garcia, Y., Caballero-Gallardo, K. and Olivero-Verbel, J. (2017): Mercury in canned tuna marketed in Cartagena, Colombia and estimation of human exposure. Food Addit. Contam. Part B Surveill., 1-7.

Bloom, N.S. (1992): On the chemical form of mercury in edible fish and marine invertebrate tissue. Can. J. Fish Aquat. Sci., 49, 1010-1017.

Boadi, N.O., Twumasi, S.K., Badu, M. and Osei, I. (2011): Heavy metal contamination in canned fish marketed in Ghana. Amer. J. Sci. Ind. Res., 2, 877-882.

Bradley, M.A., Barst, B.D. and Basu, N. (2017): A review of mercury bioavailability in humans and fish. Int. J. Environ. Res. Public Health, 14.

Burger, J. (2000): Gender differences in meal patterns: role of selfcaught fish and wild game in meat and fish diets. Environ. Res., 83, 140-149.

Burger, J. and Gochfeld, M. (2004): Mercury in canned tuna: white versus light and temporal variation. Environ. Res., 96, 239-249.

Burger, J. and Gochfeld, M. (2013): Selenium/mercury molar ratios in freshwater, marine, and commercial fish from the USA: variation, risk, and health management. Rev. Environ. Health, 28, 129-143.

Chapman, L. and Chan, H.M. (2000): The influence of nutrition on methyl mercury intoxication. Environ. Health Perspect., 108, 29-56.

Food and Agriculture Organization of the United Nations (2004):
Fish marketing and credit in Vietnam. Food and Agriculture Organization of The United Nations. Rome. ftp://ftp.fao.org/ docrep/fao/007/y5707e/y5707e00.pdf. Accessed 29 May 2017.

Food and Agriculture Organization of the United Nations (2005): FAO Fishery Country Profile: The Socialist Republic of Vietnam. FAO. http://www.fao.org/fi/oldsite/FCP/en/vnm/profile. htm. Accessed 29 May 2017.

Hoang, V.A.T., Sakamoto, M. and Yamamoto, M. (2017): Mercury and selenium levels, and their molar ratios in several species of commercial shrimp in Japan regarding the health risk of methylmercury exposure. J. Toxicol. Sci., 42, 509-517.

Joint FAO/WHO Expert Committee on Food Additives (2003): Summary and conclusion. Sixty-first meeting. Rome, 10-19, June 2003. ftp://ftp.fao.org/es/esn/jecfa/jecfa61sc.pdf. Accessed 02 June 2017.

Khan, M.A. and Wang, F. (2009): Mercury-selenium compounds and their toxicological significance: Toward a molecular understanding of the mercury-selenium antagonism. Environ. Toxicol. Chem., 28, 1567-1577.

Koriyama, C., Campos, F.I., Yamamoto, M., Serra, M., Carrasquilla, G., Carrascal, E. and Akiba, S. (2008): Toenail selenium levels and gastric cancer risk in Cali, Colombia. J. Toxicol. Sci., 33, 227-235.

McDowell, M.A., Dillon, C.F., Osterloh, J., Bolger, P.M., Pellizzari, E., Fernando, R., Montes de Oca, R., Schober, S.E., Sinks, T., Jones, R.L. and Mahaffey, K.R. (2004): Hair mercury levels in U.S. children and women of childbearing age: reference range data from NHANES 1999-2000. Environ. Health Perspect., 112, $1165-1171$.

Ministry of Health Labour and Welfare (2003): Advice for Pregnant Women on Fish Consumption concerning Mercury Contamination. http://www.mhlw.go.jp/english/wp/other/councils/mercury/. Accessed 26 June 2017.

Miyamoto, K., Kuwana, T., Ando, T., Yamamoto, M. and Nakano, A. (2010): Methylmercury analyses in biological materials by heating vaporization atomic absorption spectrometry. J. Toxicol. Sci., 35, 217-224.

Mozaffarian, D. and Rimm, E.B. (2006): Fish intake, contaminants, and human health: evaluating the risks and the benefits. JAMA, 296, 1885-1899.

National Institute of Advanced Industrial Science and Technology (2010): Trace elements, arenobetaine and methylmercury in cod fish tissue. https://www.nmij.jp/english/service/C/crm/61/7402a en.pdf Accessed 19 March 2016.

National Research Council (2000): Toxicological Effects of Methylmercury. National Academy Press. Washington (DC). http:// www.ncbi.nlm.nih.gov/pubmed/25077280. Accessed 02 June 2017.

Needham, S. and Funge-Smith, S. (2015): The consumption of fish and fish products in the Asia-Pacific region based on household surveys. Food and Agriculture Organization of The United Nations. Regional office for Asia and the Pacific. Bangkok. http://www.fao.org/3/a-i5151e.pdf. Accessed 29 May 2017.

Notice Kannyu No.99 (1973): From Director General, Environment and Hygiene Bureau, Ministry of Health and Welfare, Japan, to All the Prefectural Governors and All the Mayors in Cities Designated by Government Ordinance of Japan (in Japanese).

Otsuka, R., Yatsuya, H. and Tamakoshi, K. (2014): Descriptive epidemiological study of food intake among Japanese adults: analyses by age, time and birth cohort model. BMC Public Health, 14, 328.

Peterson, S.A., Ralston, N.V.C., Whanger, P.D., Oldfield, J.E. and 
V.A.T. Hoang et al.

Mosher, W.D. (2009): Selenium and mercury interactions with emphasis on fish tissue. Environ. Bioindic., 4, 318-334.

Roman, M., Jitaru, P. and Barbante, C. (2014): Selenium biochemistry and its role for human health. Metallomics, 6, 25-54.

Sakamoto, M., Itai, T., Yasutake, A., Iwasaki, T., Yasunaga, G., Fujise, Y., Nakamura, M., Murata, K., Chan, H.M., Domingo, J.L. and Marumoto, M. (2015): Mercury speciation and selenium in toothed-whale muscles. Environ. Res., 143, 55-61.

Sakamoto, M., Murata, K., Kakita, A. and Sasaki, M. (2012): A review of mercury toxicity with special reference to methylmercury. In: Environmental Chemistry and Toxicology of Mercury (Liu, G., Cai, Y. and O'Driscoll, N., eds.), pp.501-516, John Wiley \& Sons, Hoboken, New Jersey.

Shah, A.Q., Kazi, T.G., Afridi, H.I. and Arain, M.B. (2016): A population assessment of mercury exposure from two cities of Pakistan with respect to freshwater and marine fish consumption. Toxicol. Ind. Health, 32, 1033-1041.

Sheehan, M.C., Burke, T.A., Navas-Acien, A., Breysse, P.N., McGready, J. and Fox, M.A. (2014): Global methylmercury exposure from seafood consumption and risk of developmental neurotoxicity: a systematic review. Bull. World Health Organ., 92, 254-269F.

Shim, S.M., Dorworth, L.E., Lasrado, J.A. and Santerre, C.R. (2004): Mercury and fatty acids in canned tuna, salmon, and mackerel. J. Food Sci., 69, c681-c684.

Siedlikowski, M., Bradley, M., Kubow, S., Goodrich, J.M., Franzblau, A. and Basu, N. (2016): Bioaccessibility and bioavailability of methylmercury from seafood commonly consumed in North America: In vitro and epidemiological studies. Environ. Res., 149, 266-273.

Slotnick, M.J. and Nriagu, J.O. (2006): Validity of human nails as a biomarker of arsenic and selenium exposure: a review. Environ. Res., 102, 125-139.

Srogi, K. (2007): Mercury content of hair in different populations relative to fish consumption. Rev. Environ. Contam. Toxicol., 189, 107-130.

Thomson, C.D. (2004): Assessment of requirements for selenium and adequacy of selenium status: a review. Eur. J. Clin. Nutr.,
58, 391-402.

Thong, N.T. and Olsen, S.O. (2012): Attitude toward and consumption of fish in Vietnam. J. Food Prod. Market., 18, 79-95.

U.S. Food and Drug Administration (2001): Mercury levels in seafood species. Center for Food Safety and Applied Nutrition Office of Seafood. https://www.fda.gov/OHRMS/DOCKETS/ac/02/briefing/3872_Advisory\%202.pdf. Accessed 04 June 2017.

U.S. Food and Drug Administration (2014): Mercury Levels in Commercial Fish and Shellfish (1990-2012). https://www.fda. gov/food/foodborneillnesscontaminants/metals/ucm115644.htm. Accessed 26 June 2017.

United Nations Environment Programme (2002): Global Mercury Assessment. UNEP Chemicals Mercury Programme. http:// www.eeaa.gov.eg/cmuic/cmuic_pdfs/mercury/final-assessmentreport-25nov02.pdf. Accessed 14 June 2017.

United States Environmental Protection Agency (1997): Mercury Study Report to Congress Environmental Protection Agency. Washington DC, United States https://www3.epa.gov/ttn/ atw/112nmerc/volume1.pdf. Accessed 29 May 2017.

Weichselbaum, E., Coe, S., Buttriss, J. and Stanner, S. (2013): Fish in the diet: A review. Nutr. Bull., 38, 128-177.

World Health Organization (2008): Guidance for identifying populations at risk from mercury exposure. World Health Organization. Geneva, Switzerland. http://www.who.int/foodsafety/publications/chem/mercuryexposure.pdf. Accessed 7 April 2017.

World Health Organization (2010): Children's exposure to mercury compounds. World Health Organization. Geneva, Switzerland. http://apps.who.int/iris/bitstream/10665/44445/1/978924150045 6 eng.pdf. Accessed 03 March 2017.

Yasutake, A., Matsumoto, M., Yamaguchi, M. and Hachiya, N. (2003): Current hair mercury levels in Japanese: survey in five districts. Tohoku J. Exp. Med., 199, 161-169.

Yoshimoto, K., Van Anh, H.T., Yamamoto, A., Koriyama, C., Ishibashi, Y., Tabata, M., Nakano, A. and Yamamoto, M. (2016): Simple analysis of total mercury and methylmercury in seafood using heating vaporization atomic absorption spectrometry. J. Toxicol. Sci., 41, 489-500. 